\title{
LOS DICCIONARIOS ESPAÑOL-ÁRABE: MÁS DE CINCO SIGLOS DE LEXICOGRAFÍA BILINGÜE ${ }^{1}$
}

\author{
Francisco Vidal Castro \\ Universidad de Jaén
}

\section{RESUMEN}

Síntesis panorámica sobre los diccionarios castellano-árabe de carácter histórico (s. XVI-XIX) y sobre sus autores. El estudio se inserta en su contexto histórico-cultural y socio-lingüístico. Se realiza una presentación de cada diccionario y un análisis lexicográfico global y comparativo. Los diccionarios estudiados son los Pedro de Alcalá, Bernardino González, Francisco Cañes, Patricio de la Torre y José Lerchundi.

Palabras clave: lexicografía; diccionarios español-árabe; s. XVI-XIX; lengua árabe; lengua española.

\section{ABSTRACT}

Panoramic synthesis on the Spanish-Arabic dictionaries of historical character ( $s$. XVI-XIX) and on its authors. The study is inserted in its historical, cultural, social and linguistic context. It is carried out a presentation of each dictionary and a global and comparative lexicographical analysis. The studied dictionaries are these of the Pedro de Alcalá, Bernardino González, Francisco Cañes, Patricio de la Torre and José Lerchundi.

Keywords: lexicography; dictionaries Spanish-Arabic; s. XVI-XIX; Arab language; Spanish language.

Este artículo solo pretende ofrecer una aproximación y una síntesis sobre los diferentes diccionarios del español al árabe y sobre sus autores. Tras una contextualización históricocultural y socio-linguiística se ofrecerá la presentación de cada diccionario y tras ello un análisis global y comparativo del conjunto de esta lexicografía bilingüe castellano-árabe producida durante más de cinco siglos, desde finales del XV (cuando ya estaba preparando Pedro de Alcalá su diccionario) hasta el siglo XXI, en cuyos primeros años han aparecido

\footnotetext{
${ }^{1}$ El presente artículo se basa en un trabajo publicado anteriormente: F. VIDAL CASTRO (2000 [2001]). "Los diccionarios español-árabe: cinco siglos de lexicografía bilingüe”. Cinco siglos de lexicografía del español. IV Seminario de Lexicografía Hispánica. Jaén, 17 al 19 de noviembre de 1999, I. Ahumada (ed.), Jaén, Universidad, 239-267. Agradezco la ayuda recibida en la Biblioteca Islámica Félix María Pareja por el personal de la misma y, especialmente, por parte de Aranzazu Uzquiza Bartolomé y $\mathrm{M}^{\mathrm{a}}$ Victoria Alberola Fioravanti, directora de la Biblioteca.
} 
algunas obras de este tipo. No obstante, el campo de análisis queda delimitado en esta ocasión a la lexicografía español-árabe producida hasta el siglo XIX, por lo tanto se restringe, dentro del marco establecido por el comité de redacción de esta revista, a los diccionarios "históricos" (aparecidos en los siglos XVI-XIX) y excluye los diccionarios modernos del siglo XX y XXI.

El tema ha sido estudiado por diversos investigadores, entre los que destacan Miguel Asín Palacios, José María López, José A. Sánchez Pérez, Elías Terés, Amador Díaz, Federico Corriente, Braulio Justel, Elena Pezzi y Abdelouahab El Imrani, Ramón Lourido, entre otros, cuyos trabajos se irán citando oportunamente.

\section{INTRODUCCIÓN: HISTORIA POLÍTICA, LENGUA ÁRABE Y RELIGIÓN}

Tanto el estudio de la lengua árabe como el origen y nacimiento de la lexicografía bilingüe español-árabe hace ya más de cinco siglos surgieron indisolublemente vinculados a las relaciones entre el Islam y la Península Ibérica. Estas relaciones, que se iniciaron en el siglo VIII y todavía hoy se mantienen, suponen una historia común Islam/Península Ibérica que ha sido periodizada por $\mathrm{M}^{\mathrm{a}}$ Jesús Viguera, desde un punto de vista amplio y globalizador, en cuatro etapas:

1. musulmanes con poder político en la Península (711-1492),

2. musulmanes sin poder político (1492-1614),

3. ausencia de musulmanes (1614-segunda mitad del siglo XX) y

4. presencia de musulmanes nacionales y extranjeros (segunda mitad del siglo $\mathrm{XX})^{2}$.

En cada una de esas etapas los escritores cristianos y españoles han ido cambiando su actitud y valoración sobre el musulmán de acuerdo con los intereses políticos, religiosos y sociales del momento. Así, esa actitud ha pasado por fases de "maurofilia" y de "maurofobia", de aceptación y de rechazo. Se inicia con un planteamiento de ilegalidad territorial del Islam en la Península y necesidad de la Reconquista en la primera etapa, que se mantiene transformado en un planteamiento de ilegalidad de la permanencia mudéjar y morisca. Continúa, ya sin musulmanes en la Península, con una acusación de ilegalidad a los gobiernos islámicos para justificar el expansionismo colonial a la vez que comienza una recuperación oficial del esplendor andalusí como elemento de prestigio español frente a Europa. Ya en el siglo XIX, se inicia un estudio científico y profesionalizado de lo árabe e islámico, pero los autores decimonónicos adoptan mayoritariamente una posición beligerante en favor de la Península Ibérica cristiana y en contra de la andalusí. A

${ }^{2}$ M. J. VIGUERA (1996). “Al-Andalus y su estudio”. De civilización árabo-islámica, F. Vidal Castro (ed.), Jaén, Universidad de Jaén, 17-36. 
comienzos del siglo XX la polémica se centra entonces en la importancia (aceptada o negada) de al-Andalus en la formación de España como nación ${ }^{3}$.

Lógicamente, esta evolución político-ideológica ha determinado de manera fundamental la aparición y elaboración de obras para la enseñanza y aprendizaje de la lengua árabe, entre ellas los diccionarios bilingües español-árabe. Además, esta larga trayectoria de relaciones entre el Islam y la Península explica que estos diccionarios (castellano-árabe) sean los más antiguos de la lexicografía bilingüe española para una lengua viva extranjera, aunque lo de "extranjera" sea cuestionable pues el árabe fue en su día (s. VIII-XV) una lengua tan nativa como las otras lenguas peninsulares.

En el mismo sentido, la historia de las relaciones Islam-Península Ibérica ha determinado la producción de los diccionarios español-árabe, que se ha generado en dos fases de acuerdo con los objetivos, planteamientos y método de dichas obras.

La primera fase podría abarcar el conjunto de los diccionarios "históricos", elaborados desde la conquista final de Granada y la desaparición de al-Andalus hasta finales del siglo XIX, todos ellos con unas motivaciones y finalidad principales de proselitismo religioso. La segunda, desarrollada en el siglo XX y lo poco que llevamos de XXI, se realiza con unos objetivos y métodos más científicos y con el único fin genérico del conocimiento de la lengua en sí mismo. En el presente artículo, como ya se ha precisado al inicio del mismo, se atenderá la primera fase, es decir los diccionarios históricos.

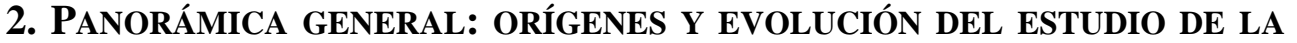 LENGUA ÁRABE EN ESPAÑA}

La lexicografía española bilingüe castellano-árabe nació tras la conquista y caída final de Granada en 1492 con un claro y definido objetivo: el proselitismo religioso. Se perseguía conocer la lengua para acceder a este grupo de población y poder catequizar y conseguir la conversión religiosa de los mudéjares. Pero este objetivo no se detiene en los límites de la Península Ibérica sino que se traslada posteriormente al otro lado del Estrecho de Gibraltar, a los países árabes, con la finalidad evangelizadora que mueve a los misioneros. Dado que la aparición de los diccionarios español-árabe surgió dentro de este marco del interés por el conocimiento de la lengua árabe, conviene realizar un breve recorrido histórico por las fases del estudio del árabe en España dedicando especial atención a la producción lexicográfica que llevó aparejada.

El inicio del interés por la lengua árabe en la Península Ibérica se sitúa en el siglo XII con la necesidad de traducir el riquísimo legado científico, técnico e intelectual de alAndalus, a su vez heredero y receptor de la cultura árabe oriental basada en la herencia semítica, indo-persa y greco-helenística. Esta labor de traducción fue realizada por un

\footnotetext{
${ }^{3}$ Ibídem. V. a., entre otras muchas referencias, el clásico J. T. MONROE (1970). Islam and the Arabs in Spanish scholarship (sixteenth century to the present), Leiden, Brill, así como los trabajos al respecto de Bernabé López García, Manuela Marín, Ma Jesús Viguera, Emilio Molina, Maribel Fierro, entre otros.
} 
conjunto de sabios de diferente religión a partir del cual se originó después la denominación de "Escuela de Traductores de Toledo". Aunque realmente no fue una escuela ni funcionó como tal, esta denominación representa la importancia cuantitativa y cualitativa del grupo de sabios políglotas y su actividad de traducción desde el siglo XII y al servicio de Alfonso $\mathrm{X}$ el Sabio, quien ordenó verter muchas obras árabes al romance e inició su uso como lengua de cultura. Por ejemplo, realizó la primera traducción castellana del Corán, de la célebre e influyente, tanto cultural como literariamente, Calila e Dimna, La escala de Mahoma y el libro Juegos del ajedrez.

Posteriormente, en el marco de las polémicas islamo-cristianas y disputas teológicas entre musulmanes y cristianos, se inicia una corriente de interés y estudio del Islam como religión y sistema de vida para combatirlo e intentar demostrar que está lleno de injusticia y error. Para ello, el mejor y más efectivo método era utilizar su mismo idioma, con lo que nace así una nueva motivación para el estudio de la lengua árabe. Sin embargo, es un interés reducido a un grupo social que es el que mantiene ese enfrentamiento teológicoreligioso, paralelo al militar, con el Islam; ese grupo social lo forman las órdenes religiosas, particularmente dominica y franciscana ${ }^{4}$.

Precisamente la orden franciscana, que ya enseñaba en sus conventos hebreo y árabe en el siglo XIII, envió en 1250 a Mallorca -conquistada por los cristianos en 1229 y Menorca en 1287- a un grupo de frailes para que aprendieran árabe.

Uno de los doce frailes que estudiaron allí fue el dominico fray Raimundo Martí, al que se le ha atribuido el Vocabularium arabico-latinum et latino-arabicum publicado en 1871 por Celestino Schiaparelli en Florencia con el título Vocabulista in arabico ${ }^{5}$. Se trata de un diccionario de gran importancia cuya autoría corresponde, según F. Corriente ${ }^{6}$, a dos autores diferentes y está escrito en caracteres árabes y latinos que los estudiosos sitúan en el siglo XIII. Recoge el árabe dialectal de la zona levantina de la Península pues

\footnotetext{
${ }^{4}$ Sobre la extensa e importante labor de los franciscanos en el mundo árabe y la lengua árabe existen numerosos trabajos; entre los más recientes se puden citar los magníficos y documentados de Ramón Lourido Díaz (1928-), responsable de la edición facsímil con amplios estudios preliminares de varios de los diccionarios que aquí se estudiarán y se citarán más adelante. Sobre este tema, v. LOURIDO (2000). "El estudio de la lengua árabe entre los franciscanos de Marruecos (siglos XIII-XVIII)". Archivo Ibero-Americano 60, 3-34; LOURIDO (en.-ag. 2006). "El estudio del árabe entre los franciscanos españoles en Tierra Santa. Colegio Trilingüe de Sevilla Colegio de Árabe de Damasco". Archivo Ibero-Americano: revista franciscana de estudios históricos 66, n. 253254, 9-240, publicado también como libro con el mismo título (Madrid, Cisneros, 2006, 267 p.). Véase además, en este mismo sentido, E. IBÁÑEZ (1948). "Acción española de los franciscanos en Marruecos". África mayo-junio, 63 y ss.; J. VALENTÍ (1910). Los estudios arábigos en España. El P. Rafael González Pérez y su notable texto gramatical de lengua árabe, Madrid, Revista de Archivos.

${ }^{5}$ R. MARTÍ (atribución) (1871). [Vocabularium arabico-latinum et latino-arabicum] Vocabulista in arabico publicato per la prima volta sopra un codice della Biblioteca Riccardiana di Firenze da C. Schiaparelli, alumno del Reale Istituto di Studi Superiori. Ed. C. Schiaparelli Da Savigliano. Florencia, Tipografia dei Succesori Le Monnier, XXXV + $641 \mathrm{p}$.

${ }^{6}$ F. CORRIENTE (1990). El léxico árabe andalusí según el "Vocabulista in aravico”, Madrid, Universidad Complutense, 7.
} 
probablemente se elaboró en el monasterio dominico de Miramar en Mallorca y ha sido estudiado por el citado Schiaparelli, Griffin ${ }^{7}$, Díaz $^{8}$ y Corriente ${ }^{9}$, entre otros.

A pesar de su antigüedad, no es este el más antiguo diccionario bilingüe al árabe que se escribió en territorio peninsular, pues el conocido como "Glosario de Leiden" (Glossarium Latino-Arabicum) es un diccionario latino para uso de mozárabes arabófonos compuesto en el último cuarto del siglo XII en Toledo con el fin de facilitarles la comprensión del latín y las Sagradas Escrituras, dado su desconocimiento del latín ${ }^{10}$. Además del valor intrínseco de estas dos obras, el Vocabulista in arabico y el "Glosario de Leiden", hay que destacar la importancia que revisten por ser los primeros diccionarios bilingües de árabe que se elaboraron en Europa, con lo que la Península Ibérica se anticipa en varios siglos a los humanistas del Renacimiento extranjeros que se dedicaron a esta labor lexicográfica.

Otro franciscano destacado en este movimiento de interés por la lengua árabe con fines catequizadores es Raimundo Llull (1235-1315), que intenta convencer a las autoridades políticas y religiosas cristianas de la importancia de la divulgación de las ideas islámicas y del vehículo de las mismas, la lengua de los infieles, para la defensa de la fe católica. Su insistencia logra de Jaime II la creación de un colegio en 1276 para enseñar a trece frailes lengua árabe con la que poder convertir después a los musulmanes ${ }^{11}$.

Ya en el siglo XV, se produce un acontecimiento fundamental para el desarrollo de estos estudios. La caída de Granada en 1492 en poder de los cristianos se produjo en forma de rendición a cambio de unas capitulaciones en las que se les garantizaba solemnemente a los musulmanes nazaríes el respeto a su vida, posesiones y cultura ${ }^{12}$. Pero los Reyes Católicos y el Estado cristiano no tardaron en violar el pacto e incumplir el juramento de tolerancia religiosa fehacientemente realizado. En 1502, tan solo diez años después de la firma del tratado, se decretó la conversión forzosa de los musulmanes granadinos, que si no

\footnotetext{
${ }^{7}$ D. A. GRIFFIN. “Los mozarabismos del 'Vocabulista' atribuido a Ramón Martí”. Al-Andalus 23 (1958), 251337; 24 (1959), 333-380; 25 (1960), 93-169.

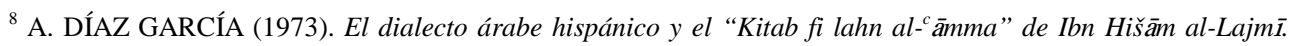
Tesis doctorales de la Universidad de Granada (resumen), nº 56. Granada, Universidad.

${ }^{9}$ CORRIENTE. El léxico árabe andalusí según el "Vocabulista in aravico”; CORRIENTE (1981). "Notas de lexicografía hispano-árabe. III. Los romancismos del Vocabulista. IV. Nuevos berberismos del hispano-árabe”. Awrāq 4, 5-30.

10 C. F. SEYBOLD (1900). Glossarium Latino-Arabicum, Berlín, Felber (edición del texto); P. Sj. van KONINGSVELD (1977). The Latin-Arabic Glossary of the Leiden University Library, Leiden, New Rhine; CORRIENTE (1991). El léxico árabe estándar y andalusí del “Glosario de Leiden”, Madrid, Departamento de Estudios Árabes e Islámicos, Universidad Complutense.

11 Sobre la interesante figura de Ramón Llull/Lull o Raimundo Lulio/Raimundus Lullus existe una amplia bibliografía; entre los trabajos más recientes se puede citar el de M. FIERRO (2008). "Apuntes sobre razón, lenguaje y conversión en el siglo XIII en la península Ibérica". Quaderns de la Mediterrània 9 (Ramon Llull y el islam, el inicio del diálogo), 295-303, así como el resto de aportaciones a este monográfico.

${ }^{12}$ Véase, por ejemplo, M. GARRIDO ATIENZA (1992 [facsímil de 1910]). Las capitulaciones para la entrega de Granada, estudio preliminar por J. E. López de Coca, Granada, Universidad, 269-295, doc. nº 60.
} 
se convertían debían exiliarse ${ }^{13}$. Los conversos que se quedaron fueron llamados moriscos y, un siglo más tarde, a comienzos del siglo XVII, se decreta su expulsión definitiva como consecuencia de las rebeliones que llevaron a cabo en contra de las presiones y agresiones económicas, jurídicas y religiosas que padecían.

En este momento aparece la figura de fray Hernando de Talavera, primer arzobispo de Granada que, además de fundar la Escuela Arábica Catequista, en su empeño catequizador de los moriscos buscó

por todas partes clérigos y religiosos que tuvieran noticia de la lengua arábica para que en ella les predicasen y enseñasen [...] procuró que muchos clérigos la aprendiesen y que hubiese lección diaria della en su casa; y para que los clérigos, curas y sacristanes del arzobispado tuviesen noticia della [...] mandó hacer Arte y Diccionario declarado en lengua y letra castellana ${ }^{14}$.

Pocos años después, ya en el siglo XVI aunque apenas comenzado, aparece la obra fundamental por una de las figuras más destacadas de este movimiento de estudio de la lengua árabe y de la lexicografía español-árabe. Se trata del fraile jerónimo Pedro de Alcalá que escribió el Arte para ligera [sic] mente saber la lengua arauiga y lo acompañó de un Vocabulista arauigo en letra castellana, impreso en Granada en 1505.

A partir de esa época, el interés por la cultura y la lengua árabe decrece debido a dos fenómenos: la expulsión de los moriscos y la vigilancia de la Inquisición que convertía en sospechoso a todo aquel que se interesara por la lengua árabe sin un motivo justificable ante el Santo Oficio. La influencia del Cardenal Cisneros acabó con la política de evangelización pacífica. Ello tuvo como consecuencia, entre otras, que la ventaja de la que España gozaba en este campo gracias a su tradición arabista se perdiera y fueran otros países como Inglaterra, Alemania y Holanda los que destacaran y en ellos se elaborasen las grandes obras de la lexicografía occidental moderna realizadas por los humanistas Schindler, Castell, Golius, Freytag y Lane.

A pesar de las circunstancias adveras, siguen existiendo en los siglos XVI y XVII personas -siempre clérigos- que se ocupan en el estudio de la lengua árabe. Así, por ejemplo, aparecen algunas figuras como el padre Guadix, Fray Diego de Guadix, que hacia 1595 elaboró un vocabulario sobre las palabras españolas (también algunas italianas, 935,

\footnotetext{
${ }^{13}$ Las fuentes árabes reflejan la desesperación y la visión amarga del lado musulmán ante este incumplimiento, así como el relato de los ataques y agresiones a los mudéjares y su emigración y asentamiento en el Norte de África. Véase VIDAL. "Historia política". En M. J. VIGUERA MOLINS (coord.). El Reino Nazarí de Granada (12321492). Política, instituciones. Espacio y economía. Historia de España Menéndez Pidal, vol. VIII-III. Madrid: Espasa Calpe, 2000, cap. IV, "Decadencia y desaparición (1408-1492)", 51-248, p. 240, nota 425.

${ }^{14}$ Fray J. de SIGÜENZA (1907-1909). Historia de la Orden de San Jerónimo, Madrid, t. II, 306, apud A. EL IMRANI (1998). Lexicografía hispano-Árabe. Aproximación al análisis de cinco diccionarios elaborados por religiosos españoles. Tesis doctoral dir. por J. Á. Porto Dapena, Madrid, Universidad Complutense, 5, accesible en línea en la siguiente dirección de la UCM [Consulta: 17/06/2008]: http://www.ucm.es/eprints/view/ creators/El_Imrani,_Abdelouahab.html. Hernando o Fernando de Talavera pertenecía también a la misma orden de los jerónimos y fue confesor del rey Fernando el Católico (V de Castilla y II de Aragón), cargo de gran influencia y prestigio.
} 
latinas, 116, y otras varias, 73, entres ellas algunas francesas) de origen árabe, tanto nombres comunes como topónimos. Este que puede ser considerado el primer diccionario de arabismos, ha sido objeto de una tesis doctoral leída en la Universidad de Jaén en 2003 por Águeda Moreno Moreno ${ }^{15}$ y de otra edición y estudio en la Universidad de Salamanca ${ }^{16}$, además de haberse utilizado para estudios históricos de botánica ${ }^{17}$, lingüística y toponimia ${ }^{18}$. También se puede citar al padre jesuita Thomas de León (1613-1690), que compone un Vocabulario Arábigo-Castellano y Arábigo-Latino cuyo manuscrito ha sido estudiado por Darío Cabanelas ${ }^{19}$. Pero, sin duda, la figura más destacada para el objeto de este trabajo es fray Bernardino González, ya en el siglo XVII-XVIII, que compuso un diccionario tripartito: español-árabe, árabe-español y latino-árabe.

Pero fue en el siglo XVIII cuando bajo Carlos III se dio un nuevo impulso a los estudios árabes $^{20}$. La llegada a España de varios monjes maronitas, especialmente el libanés Miguel

${ }^{15}$ La obra lexicográfica del padre Diego de Guadix. Edición y estudio de la 'Recopilación de algunos nombres arábigos' [c. 1593]. Dirigida por I. Ahumada Lara, defendida el 3 de julio de 2003 en la Universidad de Jaén, posteriormente publicada como: D. de GUADIX (2007). Diccionario de arabismos. Recopilación de algunos nombres arábigos, ed. y estudio M. Á. Moreno Moreno, prólogo I. Ahumada, Jaén, Universidad, donde se destaca, además de la sistematicidad y escrupulosidad del diccionario de Guadix, la gran importancia del volumen lexicográfico tratado que "consta de 4336 entradas. De ellas, sólo 1318 tienen el estatuto de topónimo, esto es, el $48 \%$ del total de la macroestructura. El resto de su nomenclatura, esto es, 2275 voces, pertenecen al léxico general. Si a esto añadimos 2874 palabras procedentes del registro de voces internas, el diccionario recoge un total de 7210 unidades [...] las algo más de seis mil voces españolas incorporadas a este repertorio representan, hasta ese momento, el conjunto más acabado de toda nuestra lexicografía monolingüe” (p. vXIII).

${ }^{16}$ D. de GUADIX (2005). Recopilación de algunos nombres arábigos que los árabes pusieron a algunas ciudades y a otras muchas cosas, edición, introducción, notas e índices de E. Bajo Pérez y F. Maíllo Salgado, Gijón, Trea, Bibliotheca arabo-romanica et islamica 3, donde se resalta que "Guadix fue un lexicógrafo concienzudo y meticuloso, dotado de un talento asombroso para definir y de una notable aptitud para escribir con amenidad [...] La Recopilación nunca llegó a imprimirse; pese a eso, el saber de Guadix se transmitió a la posteridad, aunque de forma muy sesgada e incompleta, a través del Tesoro de la lengua castellana o española (1611) de Sebastián de Covarrubias. Hasta 1886, año en que se publicó el Glosario etimológico de Leopoldo Eguílaz y Yanguas, no apareció otra obra lexicográfica enriquecida por la consulta directa de los materiales de Guadix".

${ }^{17}$ C. TRILlO SAN JOSÉ (1996). "El nombre de las plantas en el vocabulario del padre Guadix". Ciencias de la naturaleza en al-Andalus. Textos y estudios IV, C. Álvarez de Morales (ed.), Granada, CSIC-Escuela de Estudios Árabes, 165-197; TRILLO (1997). "La vegetación en el Reino de Granada en el tránsito de la época medieval a la moderna, según el Padre Guadix (s. XVI)". Transformaciones agrarias y cultura material en Andalucía Oriental y Norte de Marruecos, J. A. González Alcantud y otros (eds.), Granada, 107-128, además de otros trabajos de la autora relacionados con la ciudad guadijeña en la época de Diego de Guadix: "Agentes del Estado y mezquitas en el reino nazarí”. Historia. Instituciones. Documentos 34 (2007), 9-21.

${ }^{18}$ F. CORRIENTE (2005). "Notas lingüísticas acerca de la 'Recopilación de algunos nombres arábigos' de Diego de Guadix". Estudios de Dialectología Norteafricana y Andalusí 9, 93-114; M. Á. MORENO MORENO (2006). "Toponimia de las tierras de una frontera (Jaén) en la Recopilación de arabismos de fray Diego de Guadix (c. 1593)". VI Estudios de Frontera. Población y poblamiento. Homenaje a Manuel González Jiménez, F. Toro Ceballos y J. Rodríguez Molina (coords.), Jaén, Diputación Provincial de Jaén, 495-508, entre otros trabajos de la misma autora.

${ }^{19}$ D. CABANELAS RODRÍGUEZ, O. F. M. (1978-1979). "Vocabulario Arábigo-Castellano y Arábigo-Latino inédito, s. XVII". Miscelánea de Estudios Árabes y Hebraicos 17-18, 209-214.

${ }^{20}$ Véase para todo lo relacionado con esta cuestión del siglo XVIII el número monográfico de la siguiente revista elaborado por P. FERNÁNDEZ (1991). "Arabismo español del siglo XVIII: origen de una quimera". Cuadernos 
Casiri (1710-1791) como intérprete de lenguas orientales en la Secretaría de Estado para Asuntos Exteriores en 1748, permitió que al año siguiente se comenzara el proyecto de catalogación de los manuscritos árabes de El Escorial, que Casiri inició en $1749^{21}$.

Este fue uno de los factores que propiciaron el inicio de una escuela de arabismo español con planteamientos científicos y que hay que enmarcar dentro de la corriente de la Ilustración y el movimiento humanista europeo. Los ilustrados empezaron a ver en el estudio de al-Andalus y sus manuscritos almacenados en las bibliotecas españolas ${ }^{22}$ el descubrimiento de un esplendor científico, cultural y económico propiamente hispano y que podía ser un motivo de prestigio ante Europa, a cuyo desarrollo científico y económico el Islam andalusí había contribuido de forma decisiva.

Simultáneamente, continuaba la enseñanza del árabe y la publicación de obras destinadas a la formación de los religiosos que desempeñaban su labor catequizadora en tierras árabes. Como en siglos anteriores, seguía siendo la orden franciscana la que desarrollaba esta labor. De hecho, todas las obras del siglo XVIII que se publicaron en España con la excepción de la Biliotheca Arabico-Hispana Escurialensis ${ }^{23}$ realizada por

de la Biblioteca Islámica "Félix María Pareja” 36, 5-12, passim. Véase además J. L. CARRILLO y M. P. TORRES (1982). Ibn al-Baytār y el arabismo español del s. XVIII, Benalmádena (Málaga), Ayuntamiento, $5+57$ p.; B. LÓPEZ GARCÍA (1998). "El Islam en la Historia de España" (Introducción). Textos y obras clásicas sobre la presencia del Islam en la historia de España, López García (comp.), Clásicos Tavera, serie III ( $\mathrm{H}^{\mathrm{a}}$ de España), vol. 3, CD-ROM, Madrid, Fundación Histórica Tavera, DIGIBIS; M. C. FERIA GARCÍA (2007). "El tratado hispano-marroquí de amistad y comercio de 1767 en el punto de mira del traductor (ii). Intervención de traductores e intérpretes: daguerrotipo de la trujamanería dieciochesca”. Sendebar 18, 5-44.

21 FERNÁNDEZ. "Arabismo español del siglo XVIII", 64-65; B. JUSTEL CALABOZO (1987²). La Real Biblioteca de El Escorial y sus manuscritos árabes. Sinopsis histórico-descriptiva, Madrid, Instituto HispanoÁrabe de Cultura; A. CANO LEDESMA (2008). "En torno a El Escorial". En M. J. VIGUERA MOLINS (dir). Colecciones madrileñas. Transmisiones moriscas. Jornadas sobre manuscritos árabes: Actas, N. Martínez de Castilla, J. L. Garrot, A. I. Beneyto y M. J. Viguera (eds.), Anaquel de Estudios Árabes, Anejos 1, Serie Monografías, Madrid, Universidad Complutense, 33-42.

${ }^{22}$ Sobre los manuscritos árabes en España se ha iniciado en los últimos años la labor sistemática de revisión, inventario, catalogación, análisis material y estudio de los fondos a través de varios proyectos de investigación dirigidos por María Jesús Viguera Molins, catedrática de Estudios Árabes e Islámicos de la Universidad Complutense de Madrid. Algunos de los resultados se han plasmado en publicaciones como: VIGUERA $(2000=$ 2001). "Fondos de manuscritos árabes en Madrid". Qurtuba 5, 271-276; VIGUERA (2001 [= marzo, 2003]). "Manuscritos árabes en Barcelona, Córdoba, Granada, Guadalajara, León y Lérida". Qurtuba 6, 267-270; VIGUERA (2003). "Apuntes sobre manuscritos árabes en España”. Grapheion. Códices, manuscritos e imágenes. Estudios filológicos e históricos, J. Pedro Monferrer Sala y M. Marcos Aldón (eds.), Córdoba, Universidad, 49-74; VIGUERA (2005). "Bibliotecas y manuscritos árabes en Córdoba". Al-Mulk. Anuario de Estudios Arabistas (Real Academia de Córdoba) 5, 97-113; VIGUERA y C. CASTILLO CASTILLO (eds.) (2006). Los manuscritos árabes en España y Marruecos. Homenaje de Granada y Fez a Ibn Jaldún. Actas del Congreso Internacional. Granada 2005, Granada, El Legado Andalusí; VIGUERA (dir). Colecciones madrileñas. Transmisiones moriscas, entre otras (véase el listado de F. TORO CEBALLOS (ed.) (2008). María Jesús Viguera Molins. Biobibliografía, Alcalá la Real, Ayuntamiento, Área de Cultura, 19-20).

${ }^{23}$ M. CASIRI (1760-1770). Biliotheca Arabico-Hispana Escurialensis sive librorum omniun Mss. quos Arabice ab auctoribus magnam partem arabo-hispanis compositos Bibliotheca Cenobii Escurialensis complectitur, recensio et explanatio Opera et studio Michaelis Casiri Syro-Maronitae, Presbyteri, S. Theologiae Doctoris, Regis a Bibliotheca linguarumque Orientalium interpretatione. Madrid, Antonio Pérez de Soto. Reimp. facs. Osnabrück, 
Casiri, fueron elaboradas por franciscanos, tanto las obras de carácter lingüístico (la Gramática y el Diccionario del padre Cañes) como otras (traducción del Libro de agricultura de Ibn al- ${ }^{-}$Awwām por fray José Banqueri ${ }^{24}$ ).

Sin embargo, aunque el objetivo religioso seguía estando presente, ahora ya el padre Cañes también expresa otros motivos y, al justificar la enseñanza de la lengua árabe en su Gramática, afirma que la escribió "deseoso de contribuir por mi parte, a que se pueda aprender con facilidad una lengua no ruda, bárbara e inútil, y que algunos por ignorancia desprecian, sino elegante, erudita y utilísima, como los hombres doctos reconocen". Pero, además, aparecen otros intereses políticos y económicos, según lo indica el mismo Cañes en el Diccionario que publicó trece años más tarde al asegurar que "En la Edad presente las cosas han cambiado: la utilidad de los pueblos y del comercio han demostrado la necesidad y conveniencia de restablecer la buena harmonía con las Potencias de Oriente y África”.

Por otro lado, el desarrollo de la imprenta en Europa y en España también contribuyó a la publicación y difusión de estas obras. Concretamente, en España los impresores de libros árabes fueron los artesanos Antonio Pérez de Soto, el primero en utilizar la tipografía árabe en nuestro país y que compuso la Biliotheca Arabico-Hispana Escurialensis y la Gramática del padre Cañes, mientras que el Diccionario de este franciscano fue encargado a Antonio de Sancha (1720-1790).

En este movimiento de inicio del arabismo científico también hay que incluir al padre jerónimo Patricio José de la Torre, importante figura que publicó en 1805 una refundición del Vocabulista arauigo en letra castellana de Pedro de Alcalá, que ya contaba tres siglos.

En el siglo XIX, mientras el Romanticismo y el interés por lo exótico recorría Europa e impregnaba también el interés por al-Andalus ${ }^{25}$, el padre franciscano José Lerchundi, intérprete de árabe en Tánger, escribió varias obras de árabe dialectal marroquí entre las que se encuentra el Vocabulario Español-Arábigo del dialecto de Marruecos.

Como conclusión de todo este periodo hasta el siglo XIX podemos observar tres aspectos de esta labor de estudio de la lengua árabe en general y de elaboración de la lexicografía castellano-árabe en particular. El primero, que las personas que realizan esta labor son religiosos: jerónimos, dominicos y, sobre todo, franciscanos. El segundo, que la

Biblio Verlag, 1972. Edición en microfichas en Oviedo, Pentalfa Microediciones, 1989, 2 vols., 11x15 cm + 2 carpetillas, $5+4$ microfichas, negativo.

${ }^{24}$ IBN AL- ${ }^{\mathrm{A}} \mathrm{WWW} \overline{\mathrm{A} M}$. Kitāb al-filāha = Libro de agricultura; su autor el Doctor Excelente Abu Zacaria Iahia Aben Mohamed ben Ahmed Ebn el Awam, sevillano; traducido al castellano y anotado por Don Josef Antonio Banqueri, prior, claustral de la Catedral de Tortosa, Individuo de la Real Biblioteca de S. M., y Académico de número de la Real Academia de la Historia. Madrid: à expensas de la Real Biblioteca, en la Imprenta Real, 1802.2 vols. Reed. facs. con estudio preliminar y notas de J. E. Hernández Bermejo y E. García Sánchez (1988), Madrid, Ministerio de Agricultura, Pesca y Alimentación, IHAC, 2 vols.

25 La imagen romántica del legado andalusí, Granada, El Legado Andalusí; Barcelona, Lunwerg, [1995]; VIGUERA (2007). "La fascinación de al-Andalus en el siglo XIX". La herencia de al-Andalus, F. Roldán Castro (ed.), Sevilla, Fundación El Monte, 207-248. 
motivación es casi exclusivamente su afán evangelizador dirigido primero a los moriscos y, después, cuando estos son expulsados, a los musulmanes de países árabes. El tercero, que, a excepción del Vocabulista de Pedro de Alcalá, la mayoría de gramáticas y diccionarios español-árabe fueron realizados en los países en los que los frailes desempeñaban su labor misionera.

\section{DESCRIPCIÓN DE LOS DICCIONARIOS}

A continuación se realizará un breve análisis y presentación de cada uno de los diccionarios de forma individualizada, con una biografía sintética del autor y una bibliografía esencial.

En la exposición se sigue un orden cronológico. Los cinco diccionarios que se analizarán son el Vocabulista arauigo en letra castellana (1505) de Pedro de Alcalá, el Intérprete arábigo (1709) de Bernardino González, el Diccionario español-latino-arábigo (1787) de Francisco Cañes, el Vocabulista Castellano-Arábigo (1805) de Patricio de la Torre y el Vocabulario Español-Arábigo del dialecto de Marruecos (1892) de José Lerchundi. No me ha sido posible localizar ningún ejemplar ni obtener información sobre el diccionario de Jaime Prats titulado Vocabulario español-árabe, significados de algunos verbos, según el Alfaveto Español, que, al parecer, fue elaborado en Damasco en el siglo XVIII y cuyo manuscrito se conserva en Madrid ${ }^{26}$.

Sin duda sería conveniente y necesario realizar algunas consideraciones acerca de la lengua árabe en general -lengua semítica, con un alfabeto, gramática y sintaxis muy diferentes al castellano y las lenguas europeas- y de la lexicografía árabe en particular, pero para no exceder los límites establecidos por el comité de redacción de la revista se prescindirá de ellas. No obstante, al menos se mencionarán dos aspectos relevantes que pueden contribuir a la comprensión de algunas características y peculiaridades de estos diccionarios, uno desde un punto de vista general y otro desde el punto de vista lexicográfico.

El primero es la estrecha relación de la lengua árabe y el Islam, que la lleva a un estado de sacralización y determina la presencia del factor religioso en el surgimiento de las ciencias de la lengua.

El segundo es que mientras que los diccionarios españoles siguen de forma lógica y natural un único sistema de ordenación alfabética, los árabes medievales se ajustan a una

\footnotetext{
${ }^{26}$ En la Biblioteca Universitaria Española con el número 1791, según FERNÁNDEZ, “Arabismo español del siglo XVIII", 55. Tampoco me ha sido posible acceder a todos los diccionarios históricos ni a los originales manuscritos o sus ediciones, por lo que el estudio lexicográfico se ha realizado a partir de la bibliografía disponible; en concreto, no he podido consultar directamente el diccionario de Patricio de la Torre, por lo que su estudio está basado en los trabajos de B. Justel y A. El Imrani, principalmente.
} 
ordenación por raíces y dentro de ellas se clasifica por categorías morfológicas el conjunto de palabras que derivan de cada raíz ${ }^{27}$.

\subsection{Pedro de Alcalá y su Vocabulista arauigo en letra castellana ${ }^{28}$}

Fray Pedro de Alcalá nació hacia 1455 y perteneció a la orden de San Jerónimo. Fue confesor del primer arzobispo de Granada, fray Hernando de Talavera, también de la misma orden. Su gran conocimiento del árabe granadino logrado a los pocos años de la conquista de Granada y los graves insultos vertidos de forma ostensible en su obra contra Mahoma sugieren la posibilidad de que el fraile jerónimo fuera un morisco converso, según Amador Díaz ${ }^{29}$, o descendiente de mudéjares, según Elena Pezzi ${ }^{30}$. Sin embargo, Federico Corriente $^{31}$ cree que, al menos, no era morisco pues considera que su conocimiento del árabe era reducido, lo que le obligó, como el propio Alcalá reconoce, a recurrir a informantes nativos, y sospecha ${ }^{32}$ que podría ser judío converso por algunas entradas relacionadas con la comunidad judía que inserta en su obra.

En cuanto a su diccionario, hay que señalar que primero compuso un breve manual para el aprendizaje de la lengua árabe titulado Arte para ligera mente [sic] saber la lengua arauiga, en cuya segunda edición apareció seguido de otra obra diferente e independiente, mucho más extensa y que es el propio diccionario. Fue precisamente la recomendación del mismo Alcalá al arzobispo de Granada lo que hizo que ambas obras fueran impresas juntas.

El título del diccionario es Vocabulista arauigo en letra castellana. Según una nota que aparece en sus páginas finales, la obra se finalizó en 1501 pero no se terminó de imprimir hasta el cinco de febrero de 1505, en Granada y por el impresor Juan Varela de Salamanca. Esta edición consta de 524 páginas a dos columnas y ha sido objeto de varias reproducciones facsímiles digitales, la primera de ellas por la editorial Espasa Calpe en

\footnotetext{
27 A título de ejemplo, entre la mucha bibliografía existente al respecto y que se podría citar, véase: J. A. HAYWOOD (1960-1965). Arabic lexicography: Its history and its place in the general history of lexicography, Leiden, E. J. Brill; HAYWOOD (1986). "The entry in medieval Arabic monolingual dictionaries: some aspects of arrangement and content". The history of lexicography. Papers from the Dictionary Research Centre Seminar at

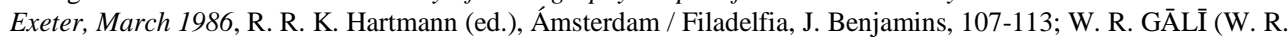

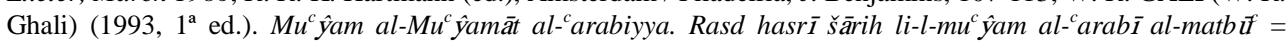
Arabic dictionaries. A comprehensive annotated bibliography of printed Arabic dictionaries, Beirut, Maktabat Lubnān.

${ }^{28}$ Existe una abundante bibliografía sobre este autor y su obra, por lo que para evitar una nota excesivamente abultada y extensa se irán citando estos trabajos en notas sucesivas insertadas en el lugar oportuno.

${ }^{29}$ DÍAZ. El dialecto árabe hispánico, 68.

${ }^{30}$ E. PEZZI (1989). El Vocabulario de Pedro de Alcalá, Almería, Cajal, 12.

${ }^{31}$ CORRIENTE (1988). El léxico árabe andalusí según Pedro de Alcalá (Ordenado por raíces, corregido, anotado y fonémicamente interpretado), Madrid, Departamento de Estudios Árabes e Islámicos, Universidad Complutense, p. II.

${ }^{32}$ CORRIENTE (1997). "La lexicografía árabe en España: pasado, presente y futuro". Pensamiento y circulación de las ideas en el Mediterráneo: el papel de la traducción, M. Hernando de Larramendi y G. Fernández Parrila (coords.), Toledo, Escuela de Traductores, Universidad Castilla-La Mancha, 133-147.
} 
Madrid en el año 2000, que consta de dos discos compactos (DVD) acompañados de un folleto de 55 páginas $^{33}$. La segunda está accesible en línea y fue realizada en 2003 por la Biblioteca Virtual Miguel de Cervantes ${ }^{34}$.

Tras su primera edición de 1505, el Vocabulista arauigo fue reeditado por Paul de Lagarde al final del siglo XIX con el título Petri Hispani de lingua arabica libri duo Pauli de Lagarde studio et sumptibus repetiti ${ }^{35}$.

Además, tres siglos después, en 1805, el diccionario sería refundido por Patricio de la Torre $^{36}$, aunque esta refundición llegó a constituir prácticamente una obra nueva de la que se hablará más abajo. En la actualidad, ha sido objeto de dos trabajos de ordenación, sistematización y anotación de su contenido por F. Corriente ${ }^{37}$ y E. Pezzi ${ }^{38}$, además de otros estudios anteriores en los que se estudió y abordó su obra por otros investigadores, como el célebre arabista holandés del siglo XIX Reinhart Pieter Anne Dozy $(1820-1883)^{39}$ o A. Díaz $^{40}$.

El Vocabulista arauigo en letra castellana es el primer diccionario español-árabe de la historia y, salvo error, el primero de la lexicografía bilingüe española que tiene como lengua extranjera de destino una lengua viva (por tanto, excluyendo al latín).

Una de sus principales características es que se trata de un diccionario cuyos términos árabes no aparecen en alifato, su propio alfabeto, sino que están transcritos en caracteres latinos. La razón que Alcalá aduce para no utilizar la grafía árabe es puramente técnica: la inexistencia de tipos de imprenta, que le obligó, además, a componer y corregir él mismo toda la obra.

\footnotetext{
${ }^{33}$ Publicado en Nuevo tesoro lexicográfico de la lengua española. Es reproducción de la edición de Granada, J. Varela, 1505. ISBN: 8423921859, O.C.; 8423921867, Disco 1; 8423921875, Disco 2.

${ }^{34}$ Es reproducción digital de la edición de Granada, Iuan varela de salama[n]ca, 1505, [540] p., 4 . Alicante, Biblioteca Virtual Miguel de Cervantes, 2003. <http://www.cervantesvirtual.com/FichaObra.html?Ref=11696> [Consulta 01/07/2008.].

${ }^{35}$ Gotinga, 1883; ed. facsímil Nueva York, Hispanic Society of America, 1928; reimp. Osnabrück, O. Zeller, 1971.

${ }^{36}$ B. JUSTEL CALABOZO (1984). "La refundición del 'Vocabulista arábigo en letra castellana' por Patricio de la Torre: propuesta de edición", Mu'tamar al-Hadāra al-Andalusiyya; JUSTEL (1984). "El Vocabulista de Alcalá y su refundición por Patricio de la Torre". Sharq al-Andalus 1, 35-46; JUSTEL (1987). "Cambios introducidos por Patricio de la Torre en su refundición de su Vocabulista arauigo de Pedro de Alcalá", Homenaje al Prof. Darío Cabanelas Rodríguez, O.F.M., con motivo de su LXX aniversario, Granada, Universidad, t. I, 29-36.

${ }^{37}$ CORRIENTE (1988). El léxico árabe andalusí según Pedro de Alcalá (Ordenado por raíces, corregido, anotado y fonémicamente interpretado), Madrid, Departamento de Estudios Árabes e Islámicos, Universidad Complutense, 200 p.; CORRIENTE (1990). "Notas adicionales a la edición del léxico árabe andalusí de P. de Alcalá". Al-Qantara 10, 413-451.

${ }^{38}$ PEZZI (1989). El Vocabulario de Pedro de Alcalá, Almería, Cajal, 749 p.

${ }^{39}$ DOZY (1881). Supplément aux dictionnaires arabes, Leiden, Brill; reimp. Beirut, Librairie du Liban, 1991, I, "Préface", V-XV.

${ }^{40}$ DÍAZ. El dialecto árabe hispánico.
} 
Precisamente esta característica es la que le otorga al diccionario su valor más importante a la vez que es el origen de sus mayores defectos. Por una parte, la transliteración permite conocer la pronunciación real y las formas dialectales del árabe granadino, pues el propio autor manifiesta que se trata de un "vocabulista de la habla comun vsada de la gente deste reyno de Granada". Es decir, pretende describir única y especialmente el dialecto nazarí dejando de lado la lengua árabe clásica, culta o estándar. Téngase en cuenta que la grafía árabe no dispone de capacidad para reflejar la acentuación y los alófonos vocálicos, pues aparte de no tener un signo para el acento solo contempla tres vocales. Además, como destaca Corriente ${ }^{41}$, los signos diacríticos supralineales e infralineales que Pedro de Alcalá inventa para reproducir los fonemas consonánticos árabes constituyen una labor pionera que se adelanta en varios siglos a la que realizaron los arabistas europeos y supone un importante avance con respecto al sistema medieval de letras combinadas con la h que generaban digramas como 'th', 'dh', etc.

Pero, por otra parte, la defectuosidad e imprecisión del sistema de transcripción impide la correcta identificación de muchas palabras y genera numerosas confusiones y ambigüedades. Por ejemplo, es un problema la falta de diacríticos suficientes para distinguir ciertos fonemas árabes que no existen en castellano, como las consonantes velares, o para indicar la cantidad vocálica y los fonemas suprasegmentales. La falta de sistemática se extiende a la fonética combinatoria, pues las asimilaciones en contacto se representan de forma poco metódica.

La falta de rigor en la transcripción se agrava considerablemente con un problema mayor aún cual es las serias y peligrosas deficiencias tipográficas.

Otras dificultades que entraña el manejo de la obra son la falta de un estricto orden alfabético y las variantes ortográficas de las voces castellanas.

Pero todo ello no merma la gran importancia ni empaña el enorme mérito de la obra, que resulta utilísima aunque haya de manejarse teniendo muy presente el condicionamiento fonológico castellano de sus grafías. Además, los citados trabajos lexicográficos de Corriente y Pezzi facilitan el manejo del diccionario ya sistematizado y depurado de los numerosos errores y erratas que presentaba la edición original.

En el mismo sentido hay que señalar que para resolver los problemas que esta transcripción en caracteres latinos ofrecía, el gobierno español encargó a Patricio de la Torre en 1797 que revisara y reescribiera en caracteres árabes el diccionario de Alcalá, labor que se plasmó en la refundición ya mencionada y que se analizará en un apartado posterior.

Por lo que respecta a la macroestructura del Vocabulista arauigo en letra castellana, presenta una división en tres categorías idéntica a la seguida por la teoría gramatical árabe: la primera dedicada al verbo, la segunda al nombre y la tercera a adverbios, conjunciones y preposiciones. Dentro de cada categoría, sigue un orden alfabético ateniéndose a su fuente,

${ }^{41}$ CORRIENTE. "La lexicografía árabe en España". 
el diccionario de $\mathrm{Nebrija}^{42}$, pero la alfabetización presenta algunos errores que Alcalá achaca al Vocabulario nebrisense.

Por otro lado, incluye una introducción inicial con instrucciones para el manejo del texto árabe y la explicación de su sistema de transcripción, entre otras observaciones.

El texto aparece con una disposición en columnas, de manera que cada voz castellana va seguida de su correspondiente árabe.

En cuanto a la microestructura y la ordenación interna de los artículos, cuando se trata de un verbo, se ofrece el equivalente árabe en tres términos: primera persona del singular del imperfectivo de indicativo y del perfectivo y segunda persona del singular del imperativo, dispuestos en tres columnas, sistema con el que se da la pauta completa de la conjugación de un verbo en árabe. Se agrupan todas las variantes o matices verbales bajo el mismo artículo (andar delante, andar detrás, andar vagando, andar perdido, etc.). Hay que advertir que el limitado conocimiento de la lengua árabe que tiene Alcalá le lleva a completar paradigmas y ofrecer formas inexistentes como imperativos de verbos pasivos, pasivas de intransitivos o primeras personas de verbos impersonales. Cuando se trata de un sustantivo, se indica el equivalente árabe y su plural separado por un punto, a veces expresado de forma íntegra y a veces de forma abreviada cuando es un plural externo o regular y basta con la terminación para expresarlo.

El corpus léxico recogido procede de una fuente que el propio Pedro de Alcalá indica en su prólogo. Se trata, al igual que otras obras de lexicografía bilingüe española y como ya se ha mencionado más arriba, del Vocabulario español-latino de Antonio de Nebrija. Sin embargo, también advierte de que ha realizado algunas modificaciones consistentes en suprimir ciertas palabras poco usuales o de difícil traducción al árabe y añadir otras nuevas. Efectivamente, así sucede, como ha demostrado $\mathrm{M}^{\mathrm{a}} \mathrm{Paz}$ Torres con respecto al campo de la ictionimia $^{43}$, en el que Alcalá modifica el léxico de Nebrija para adaptarlo al entorno granadino, si bien en otros campos no se producen esas modificaciones y adaptaciones, como ocurre con la toponimia, estudiado por Carmen Barceló y Ana Labarta ${ }^{44}$ y que se comentará a continuación, o en algunas partes de la obra, como la correspondiente a la letra A, estudiada por Gloria Guerrero Ramos ${ }^{45}$.

Aunque el diccionario no pretende ser exhaustivo ni completo, es bastante amplio. Además de sustantivos comunes, recoge numerosos -más de un centenar- nombres propios, algunos de ellos de personajes históricos: "Lucano poeta cordoues", "Mahoma

${ }^{42}$ E. A. de NEBRIJA (¿1495?). Vocabulario español-latino, Salamanca. Reimp. facsímil Madrid, Real Academia Española, 1951, 1989.

${ }^{43}$ M. P. TORRES PALOMO (1990). "La ictionimia en el 'Vocabulista' de Alcalá”. Ciencias de la naturaleza en al-Andalus. Textos y estudios I, E. García Sánchez (ed.), Granada, CSIC-Escuela de Estudios Árabes, 43-56.

44 C. BARCELÓ y A. LABARTA (1995). "La toponimia en el Vocabulista de Pedro de Alcalá". Homenaje al Profesor José María Fórneas Besteiro, Granada, Universidad, t. I, 337-355.

${ }^{45}$ G. GUERRERO RAMOS (1992). "La lexicografía bilingüe desde Nebrija a Oudin”. EURALEX '90. Actas del IV Congreso Internacional (Benalmádena, 1990), Barcelona, Bibliograf, 463-471. 
principe de los moros", "Salomon rey delos judíos", "Uidal nonbre de varon"46. Igualmente, resultan abundantes los topónimos (unos doscientos ochenta), que abarcan la Península Ibérica, Italia, Francia y otros países europeos y no europeos: "Africa", "Alemaña", "Cartama villa"; el motivo de tal abundancia es que Alcalá mantiene casi todas las entradas de Nebrija, a pesar de su inutilidad y de que se vea obligado a poner un equivalente árabe inexistente o desconocido para él o sus informadores, razón por la que incurre en numerosas incorrecciones ${ }^{47}$.

En relación con los topónimos hay que señalar los frecuentes gentilicios que selecciona: "jaenés cosa de allî", "lisbones cosa de ally", de los que, como ocurre también con los topónimos, muchos resultan innecesarios por no tener equivalente árabe o ser irrelevantes: "jaques cosa desta cibdad" (Jaca), "panplones cosa desta cibdad".

Otra peculiaridad del léxico seleccionado son las numerosas palabras malsonantes o tabú, de carácter sexual o escatológico: "caualgar la mujer", "caualgar macho a macho", “cagar”, “cojon”, “coño”, “culo”, "puta ramera”, "puto que padece”, "puto que haze”.

El gran interés del Vocabulista de Alcalá en diversos campos ha hecho que sean numerosos los investigadores que lo han abordado desde múltiples perspectivas, como los ya citados de A. Díaz, F. Corriente, E. Pezzi, Mª P. Torres Palomo, A. Labarta y C. Barceló o A. El Imrani ${ }^{48}$, entre otros.

\subsection{Bernardino González y su Intérprete arábico ${ }^{49}$}

Apenas se dispone de datos biográficos de Bernardino González. Nació hacia 1665 y murió en torno a 1735. Se sabe que era monje franciscano de la provincia franciscana de la

\footnotetext{
${ }^{46}$ Sobre estos nombres se ha realizado un estudio de antroponimia: LABARTA y BARCELÓ (1991). "La antroponimia en el Vocabulista de P. de Alcalá”. Estudios dedicados al profesor Juan Martínez Ruiz, Granada, Universidad, 105-111.

${ }^{47}$ BARCELÓ y LABARTA. "La toponimia en el Vocabulista de Pedro de Alcalá".

${ }^{48}$ EL IMRANI. Lexicografía hispano-Árabe, cap. I, 23-51.

${ }^{49}$ Aunque también existen diversos trabajos sobre este autor y su diccionario, la bibliografía sobre ambos es más reducida que la referente a Pedro de Alcalá, por lo que se reúne en esta nota: M. ASÍN PALACIOS (1901). "El intérprete arábigo de Fr. Bernardino González. Nota bibliográfica". Boletín de la Real Academia de la Historia 38, 267-279, reproducido en Obras escogidas, Madrid, 1948, 15-28; A. EL IMRANI (1998). Lexicografía hispanoÁrabe. Aproximación al análisis de cinco diccionarios elaborados por religiosos españoles, tesis doctoral dir. $\mathrm{J}$. Á. Porto Dapena, Madrid, Universidad Complutense, cap. II, 134-170; EL IMRANI (2003). "Localización de nuevos manuscritos del Intérprete arábigo de Bernardino González”. Anaquel de Estudios Árabes 14, 129-135; Fr. B. GONZÁLEZ, OFM (2005). Intérprete arábico. Epítome de la gramática arábiga. [Obras manuscritas], estudio preliminar de R. Lourido Díaz, Madrid, Real Academia de la Historia, Ministerio de Asuntos Exteriores y de Cooperación, 2 vols., $639+657$ pp., reseña en Awrāq 23 (2006), 349-356 (disponible en http://www.aeci.es/09cultural/05bibli/5pubs/arabe/awraq.htm [Consulta: 17/02/2008]) y reseña de Ladislav DROZDÍK (2006). "Fr. Bernardino González and the Spanish lexicographical tradition". Asian and African Studies (Bratislava) 15/1, 103-107; J. I. PÉREZ ALCALDE (2006). "Manuscritos árabes en la Universidad Complutense de Madrid". Los manuscritos árabes en España y Marruecos. Homenaje de Granada y Fez a Ibn Jaldún. Actas del Congreso Internacional. Granada 2005, M. J. Viguera y C. Castillo (eds.), Granada, El Legado Andalusí, 91-118, 97-99 y 105-108 (láminas en color).
} 
Concepción, con sede central en Valladolid. Estudió lengua árabe en la Escuela trilingüe de Sevilla, desde los inicios de su fundación, con el P. José de León, que fue quien comenzó la elaboración del Intérprete arábico, según reconoce el propio Bernardino González en el prólogo de su obra ${ }^{50}$. Tras dos años de estudio de árabe en Sevilla, se trasladó a Damasco en 1697 para proseguir y perfeccionar sus estudios y, tras ello, componer su diccionario, a la vez que desarrollaba la actividad misionera, que también realizó en Belén y Ramla. Hacia 1710 regresó a España, donde permaneció hasta su muerte en 1735, aproximadamente ${ }^{51}$.

El título de su obra es el siguiente: Interprete arabi[c]o castellano. El qual en lengua araba da interpretada la castellana. Compuesto y ordenado por el P. F. Bernardino González. Kitāb Turŷumān isbāniyūl wa- ${ }^{c}$ arabī = Interprete hispano-arabico. Se conserva en manuscrito del que se conocen siete ejemplares, el más antiguo de ellos una copia de 1707-1708 realizada en Damasco y actualmente depositada en la gran Biblioteca Islámica "Félix María Pareja" de Madrid, una de las más importantes bibliotecas en fondos de estudios árabes e islámicos de Europa ${ }^{52}$. Los otros ejemplares se hallan en esta y otras bibliotecas de Madrid, uno en Santiago de Compostela y otro extraviado ${ }^{53}$. El manuscrito ha sido reproducido en una publicación actual que reúne tanto el Intérprete arábico como su otra obra, con la que se complementa, el Epítome de la gramática arábiga ${ }^{54}$. Es una obra relativamente breve.

Acerca de su macroestructura, hay que señalar que se compone de tres partes dedicadas a sendos glosarios: español-árabe (Intérprete arábico-castellano, I, 1-433), árabe-español (Intérprete hispano-arábico, II, 1-416) y latino-árabe (Intérprete árabo-latino, I, 437-455). Las más de ochocientas páginas de las que consta aparecen divididas en dos columnas, en cada una de las cuales se incluye la entrada con su correspondiente equivalencia. Sigue un orden alfabético, aunque con algunas alteraciones y excepciones.

\footnotetext{
${ }^{50}$ GONZÁLEZ. Intérprete arábico, t. II, 2-3.
}

${ }^{51}$ EL IMRANI. Lexicografía hispano-Árabe, 144; LOURIDO. "Estudio preliminar" (de B. González). En GONZÁLEZ. Intérprete arábico, t. I, 22-41 y, sobre la interesante Escuela o Colegio Trilingüe de Sevilla, primera escuela de idiomas, $42-88$

${ }^{52}$ Biblioteca que originariamente pertenecía al anterior Instituto Hispano-Árabe de Cultura, transformado después en Instituto de Cooperación con el Mundo Árabe, con sucesivas modificaciones hasta la actual denominación de Instituto de Cooperación con el Mundo Árabe, Mediterráneo y Países en Desarrollo, incluido en la Agencia Española de Cooperación Internacional, de la que depende actualmente la Biblioteca. La catalogación completa de uno de los manuscritos que posee la biblioteca apareció en Cuadernos de la Biblioteca Islámica Félix María Pareja 108 (2001/2), 16: Interprete arabi[c]o castellano. El qual en lengua araba da interpretada la castellana. Compuesto y ordenado por el P. F. Bernardino González. Kitāb Turŷumān isbāniyūl wa- ${ }^{c}$ arabī $=$ Interprete hispano-arabico, [Damasco, 1709?], 29 cm., signatura 4M-2, R. 39572.

${ }^{53}$ Sobre los distintos manuscritos y sus avatares, véase EL IMRANI. "Localización de nuevos manuscritos"; LOURIDO. "Estudio preliminar" (de B. González). En GONZÁLEZ. Intérprete arábico, t. I, 11-22; PÉREZ ALCALDE. "Manuscritos árabes en la Universidad Complutense de Madrid".

${ }^{54}$ GONZÁLEZ. Intérprete arábico. Epítome de la gramática arábiga. [Obras manuscritas]. Véase la referencia completa y reseñas sobre la misma supra, nota 49. 
Con respecto a la microestructura, las entradas presentan, esporádicamente, sinónimos o terminación de femenino y plural, pero casi nunca indica la categoría gramatical. Ofrece las equivalencias árabes en alifato sin vocalizar (indica alguna que otra vocal, pero no todas ni en todas las palabras) y con plural y, en alguna ocasión, con su femenino. Por ejemplo, para “copo.s (sic) de nieve" ofrece la equivalencia “- $\mathbb{K}$ "آت Recurre a agrupaciones ideológicas de términos y expresiones relacionados con la entrada y emplea algunas abreviaturas, como "idem" o " $v$." (vide), en este último caso para remitir a otras entradas, como por ejemplo en el caso de "Composición, ajuste. vide ajuste, concordia" (I, 94).

En el corpus léxico, aunque también se incluyen nombres propios de persona, al igual que Alcalá, estos son escasos, mientras que los topónimos y gentilicios se circunscriben a los procedentes de Tierra Santa: Jerusalem, Jesuchristo (I, 233), Damasco, damasceno (I, 115), Italia, -no, Jacob, Jacobita.s (I, 232). Las palabras groseras, que en español se presentan con eufemismos, se vierten al árabe con términos vulgares, quizás por el conocimiento que la actividad en el confesionario proporcionó al fraile, que consideraría necesaria la comprensión de estos términos árabes por sus compañeros misioneros. El vocabulario de carácter religioso relativo al islam es muy escaso (Mahoma, Mahometano: I, 252; Mezquita.s I, 266; Ablución de los turcos, I, 4), mientras que el relativo al cristianismo es bastante amplio (Papa, Papado: I, 295; Evangelista.s, Evangelico, Evangelio, Evangelicamente, Evangelizar, Eucharistia: I, 174-175; Eclesiástico, Eclesiastes. lib. sac.: I, 147; Sacrificar decir misa: I, 374). Por último, es de destacar la presencia del dialecto siriopalestino en aspectos de fonética y léxico.

\subsection{Francisco Cañes y su Diccionario español-latino-arábigo ${ }^{55}$}

Francisco Cañes nació el 1 de marzo de 1720 en Valencia, donde también falleció el 4 de mayo de 1795. Ingresó en la provincia franciscana de San Juan Bautista en Valencia. El 7 de septiembre de 1755 partió desde Alicante hacia Tierra Santa y allí vivió en Jerusalén y Damasco, ciudad esta última en la que fue párroco y profesor de árabe en el colegio franciscano español. El 11 de enero de 1771 regresó a Valencia y profesó en el colegio franciscano de Benigámin. Amigo personal y capellán del Conde de Campomanes, fue llamado a Madrid para trabajar en la que se titularía Gramática árabe-española ${ }^{56}$ y ejercer de lector de lengua árabe en el colegio franciscano de Madrid, fundado en 1772 para enseñanza del árabe a los frailes ${ }^{57}$.

Su obra lexicográfica se titula Diccionario español-latino-arábigo en que siguiendo el diccionario abreviado de la Academia se ponen las correcciones latinas y árabes, para

\footnotetext{
55 E. TERÉS (1956). "El Diccionario Español-Latino-Arábigo del P. Cañes”. Al-Andalus 21, 255-276; EL IMRANI. Lexicografía hispano-Árabe, 171-262.

${ }^{56}$ F. CAÑES. Gramática arábigo-española, vulgar y literal con un diccionario arábigo-español, en el que se ponen las voces más usadas para una conversación familiar, con un texto de la doctrina cristiana en el idioma arábigo. Madrid: Antonio Pérez de Soto, 1775. XVII+272 p. Un ejemplar de esta gramática se halla depositado en la Biblioteca Islámica "Félix María Pareja” de Madrid con la signatura C-34/I.

${ }^{57}$ FERNÁNDEZ. "Arabismo español del siglo XVIII”, 64-65.
} 
facilitar el estudio de la lengua arábiga a los misioneros, y a los que viajaren a contratar en África y Levante. Fue editada en Madrid por el impresor Antonio Sancha en 1787. Consta de tres volúmenes de gran formato y un ejemplar de la misma se halla en la citada Biblioteca Islámica "Félix María Pareja" de Madrid". Además, existen ejemplares en diversas universidades (Barcelona, Cádiz, Complutense de Madrid, Murcia, Navarra, Salamanca, Santiago de Compostela, Valencia) e instituciones (Biblioteca de Catalunya, CSIC).

El prólogo escrito por el conde de Campomanes constituye un interesante e importante documento para la historia del arabismo español. Bajo el título de "Discurso preliminar sobre la utilidad de la lengua arabiga" hace un repaso y balance de los estudios de la lengua y lexicografía árabe en España y destaca su utilidad para la identificación de los arabismos.

La correspondencia conservada del conde de Campomanes (Pedro Rodríguez Campomanes) revela numerosos detalles sobre la composición tipográfica del Diccionario de Cañes. La edición fue encargada a Joaquín Ibarra (1726-1785), impresor de la Cámara del Rey, pero murió en 1785 y el trabajo hubo de trasladarse a la imprenta de Antonio de Sancha. Este realizó una lujosa impresión con magníficos grabados de Fernando Selma en la primera página de cada uno de los tres volúmenes; en estos grabados aparece, respectivamente, la presentación de la obra al rey, la Fe sobre una ciudad amurallada y el comercio entre España y el Levante.

La revisión del diccionario correspondió a Miguel Casiri, pero su avanzada edad setenta y seis años- $u$ otros motivos le llevaron a solicitar en 1786 un ayudante para la ardua tarea. El conde de Campomanes intentó proporcionarle dicho auxiliar en la persona de fray Pedro de Madrid, pero no lo consiguió ya que su propuesta fue desestimada por la mala reputación de este monje ante sus superiores. Tampoco consiguió Campomanes que se le abonara a Casiri los cuatrocientos doblones sencillos que este había pedido por el trabajo de revisión completa del Diccionario $^{59}$.

El objetivo de la obra es, lógicamente, facilitar el aprendizaje y uso de la lengua árabe hablada en Próximo Oriente a los destinatarios a los que va dirigida y que aparecen expresamente indicados en el título: religiosos, viajeros y comerciantes.

Utiliza el orden alfabético y en su microestructura presenta la entrada en mayúsculas seguida de su equivalente latino en cursiva y minúscula, tras el cual coloca el equivalente árabe. En las entradas añade ocasionalmente sinónimos o definiciones y las observaciones de tipo gramatical son abundantes. Emplea marcas lexicográficas (señala con un asterisco los arabismos) y numerosas abreviaturas que reúne en un listado. Al igual que Bernardino González, también recurre a las agrupaciones ideológicas.

\footnotetext{
${ }^{58}$ Con las signaturas $66 / \mathrm{O}$ (v. 1), 67/O (v. 2) y 68/O (v. 3). También dispone esta Biblioteca (signatura F-16$18 / 2 \mathrm{C}$ ) de otra copia y de un microfilm de la obra.

${ }^{59}$ FERNÁNDEZ. “Arabismo español del siglo XVIII", 11-12, 16-25, 48-49.
} 
Por lo que atañe al corpus léxico, procede del Diccionario abreviado de la Real Academia Española de $1780^{60}$, pero añade numerosos vocablos nuevos. Aunque apenas aparece una docena de nombres propios, casi todos de carácter bíblico, con la excepción del Profeta Muhammad, se puede destacar la presencia de muy numerosos y diversos topónimos y gentilicios que, además, contienen en algunos casos un desarrollo enciclopédico con información sobre el lugar indicado. De las palabras groseras y tabú se da el equivalente en árabe clásico o estándar. El vocabulario religioso islámico es mínimo y básico (Alcorán, hégira, mezquita), aunque se mantiene intencionadamente una actitud respetuosa hacia el Islam; en cambio, el vocabulario religioso cristiano es extenso y completo. Igualmente, reviste cierta importancia la información sociológica que encierra sobre árabes y turcos orientales, cosa que también ocurre a nivel lingüístico, pues, aunque recurre primordialmente al árabe clásico, también introduce una gran proporción de dialectal sirio, tanto en la fonética como en la gramática y el léxico.

Por último y como información complementaria se puede añadir que Cañes también compuso otro diccionario que incorporó a su gramática ya citada para acompañarla y servir de apoyo a la conversación, tal y como informa el mismo título ${ }^{61}$.

\subsection{Patricio de la Torre y su Vocabulista Castellano-Arábigo ${ }^{62}$}

Nacido en Orgaz (Toledo) en 1760, Patricio José de la Torre ingresó a los dieciséis años en el Monasterio de El Escorial. Convertido ya en monje jerónimo, alcanzó la cátedra de árabe en el Colegio de San Lorenzo de El Escorial en 1786 con unos ejercicios sobre gramática y poética de los árabes que se publicaron al año siguiente ${ }^{63}$. En 1787 fue nombrado bibliotecario segundo de la Real Biblioteca del monasterio. Obtuvo una ayuda de Jovellanos que lo envió a Tánger en 1797 para ampliar sus conocimientos de árabe clásico y estudiar el dialecto marroquí con el fin de refundir el Vocabulista de Alcalá. Tres años después acompañó a la misión médica española en Mequínez y Fez en 1800 para ayudar contra la peste a la familia real. En 1803 fue nombrado académico correspondiente de la Real de la Historia e interviene como catedrático en unas oposiciones de lengua árabe para

\footnotetext{
${ }^{60}$ REAL ACADEMIA ESPAÑOLA (1780). Diccionario de la lengua castellana compuesto por la... Madrid.

${ }^{61}$ Véase supra, nota 56.

${ }^{62}$ Tras una breve reseña por J. A. SÁNCHEZ PÉREZ (1953). "Un arabista español del siglo XVIII: Fray Patricio José de la Torre". Al-Andalus 18, 450-455, la figura, las obras y el diccionario de Patricio de la Torre han sido ampliamente estudiados por B. Justel en los tres artículos ya citados (v. supra, nota 36), otro más ("La 'Gramática de la lengua arábigo-erudita' y su infundada atribución a Patricio de la Torre”. Sharq Al-Andalus 7, 1990, 31-35) y un libro (El toledano Patricio de la Torre: monje escurialense, arabista y vicecónsul en Tánger, El Escorial, Ediciones Escurialenses, 1991), a lo que se ha añadido, recientemente, el trabajo de EL IMRANI. Lexicografía hispano-Árabe, cap. II, 52-132. V. a. las referencias señaladas en las siguientes notas. No me ha sido posible acceder a este diccionario.

${ }^{63}$ P. de la TORRE (Jer.). Ensayos sobre la gramática y poética de los árabes que ofrecen al público examen ... Fr. Patricio de la Torre ... y Don Miguel Garcia Asensio ... en los Reales Estudios de San Isidro, asistidos de su maestro ... Don Mariano Pizzi ... ; Precede un Discurso sobre la necesidad y utilidad de este idioma ... Madrid: En la Imprenta de Don Antonio de Sancha, 1787, [2], IV, III-LXXXVIII p.
} 
asistir a Miguel de Piedralaves ${ }^{64}$. En 1810 fue designado vicecónsul de Tánger, cargo que no ejerció, y traductor oficial del ministerio de Estado. De estos años, 1809-1810, se han conservado varias cartas que dirigió a Fernando VII ${ }^{65}$.

Es autor de unas dieciséis obras, algunas sobre Marruecos. Además del diccionario, compuso una Gramática arábigo-castellana.

El título completo de su diccionario es Sirāŷy al-luga al- ${ }^{c}$ aŷamiyya al-manqūla min alluga al-isbanyūliyya ilà l-carabiyya. Vocabulista Castellano-Arábigo, compuesto y declarado en letra y lengua castellana por el M. R. P. Fray Pedro de Alcalá, del órden de San Jerónimo, corregido, aumentado y puesto en caracteres arábigos por el P. Fray Patricio de la Torre, de la misma órden, bibliotecario y catedrático de la lengua arábigoerudita en el Real monasterio de San Lorenzo del Escorial.

La magnitud de la obra le obligó a dedicarle casi diez años de trabajo, entre 1798 y 1808. Para elaborarlo realizó su primer viaje a Marruecos ya mencionado. Se conservan depositados en El Escorial tanto los manuscritos originales como la edición incompleta que se realizó, pues se comenzó a imprimir en 1805 y la invasión napoleónica impidió su conclusión.

El manuscrito consta de 559 hojas escritas a dos columnas.

Como su título indica, se trata de una refundición del diccionario de Pedro de Alcalá. Su origen está en el encargo que el gobierno español realizó a Patricio de la Torre para que pusiera en caracteres árabes el Vocabulista de Alcalá con el fin de facilitar su dificultosa consulta y utilización por las razones ya expuestas en el correspondiente apartado. Al mismo tiempo revisó y corrigió toda la obra hasta el punto de que el resultado puede considerarse una obra nueva y distinta. Los cambios introducidos por fray Patricio fueron, por tanto, numerosos y han sido estudiados específicamente por B. Justel ${ }^{66}$.

Entre sus características generales se puede citar la inclusión con cierta frecuencia de observaciones gramaticales, como la indicación de la categoría gramatical de la palabra, así como la explicación de algunos arabismos en nombres comunes y topónimos y la

\footnotetext{
${ }^{64}$ Así lo pone de manifiesto la publicación de los ejercicios, como ocurriera en el caso del propio Patricio de la Torre: v. M. de PIEDRALAVES (1804). Exercicios de toda la gramática arábigo-erudita que sustentará el P. Fr. Miguel de Piedralaves, asistido de el P. Fr. Patricio de la Torre, Madrid, Sancha. Esta obra, con paginación múltiple, también incluye otros "ejercicios" similares para hebreo: Exercicios de la lengua hebrea sobre el libro del Éxodo que interpretará en idioma castellano el P. Fr. Joaquín Illán; asistido de su catedrático el P. Fr. Francisco Cifuentes, y para griego: Examen público sobre las instituciones de la lengua griega que tendrá en su monasterio de S. Lorenzo el Real el P. Fr. Francisco Campos; asistido del catedrático de dicha lengua Fray Juan de Soto.

${ }^{65}$ P. de la TORRE. [Tres cartas de] Fr. Patricio de la Torre a Fernando VII, 7 agosto bal, Cádiz 27 diciembre 1809 - 7 septiembre 1810. [S.1.: s.n., s.a.] [9] h. Las cartas se encuentran en el Archivo Histórico Nacional, Sección Estado, leg. 5817 y una copia de las mismas se halla depositada en la Biblioteca Islámica "Félix María Pareja" de Madrid (signatura: ARR Arch 34/2425) procedente del Archivo del Fondo Arribas Palau (copia de Arribas Palau, texto mecanografiado; la segunda carta está, además, manuscrita, probablemente por M. Arribas).

${ }^{66} \mathrm{~V}$. los trabajos citados supra, notas 36 y 62.
} 
utilización de abreviaturas. Igualmente, son de gran interés los refranes y proverbios árabes y la información sociológica que alberga en relación con la cultura, costumbres e instituciones árabes e islámicas, en general, y marroquíes, en particular (como fórmulas de saludo y otras). Por ello, la mayoría son palabras y expresiones del árabe marroquí y, en menor medida, de árabe clásico.

En este sentido es de destacar la similitud de la lengua de Alcalá con el árabe marroquí del siglo XVIII que constata Patricio de la Torre en el prólogo a su obra, donde dice:

Es, en verdad, cosa prodigiosa: han corrido tres siglos desde que se imprimió este diccionario hasta nuestro tiempo, y su lenguaje es el mismo que hoy se habla en el imperio de Marruecos. Sólo hay una diferencia, y es que el del P. Alcalá, que era el mismo que hablaban los moros de Granada, es más correcto y se acerca más a las reglas de la gramática escrita, y el que en el día hablan en Berbería abunda en defectos gramaticales ${ }^{67}$.

Uno de los inconvenientes que presenta la refundición frente al original de Alcalá deriva, precisamente, de lo que también le proporciona grandes ventajas: al estar en grafía árabe la refundición no puede indicar, como hace Alcalá, el acento, la imela (pronunciación de la vocal 'a', generalmente cuando es larga, como 'e' o 'i') o las vocales 'e' y 'o', para las que el árabe no dispone de grafema alguno.

Por lo que respecta a la macroestructura, Patricio de la Torre sigue el orden alfabético de manera rigurosa, corrigiendo las alteraciones de Alcalá y modernizando la grafía castellana ('jabalí' por 'jauali', 'decir' por 'dezir'). Por otro lado, suprime la división en tres bloques (verbo, nombre, partícula) que Alcalá realizó y los unifica en uno solo.

Entre las cuestiones relacionadas con la microestructura del Vocabulista CastellanoArábigo, se debe señalar que las entradas aparecen en mayúsculas seguidas, cuando los hay, de los sinónimos en minúsculas y, como es habitual, en el extremo opuesto de la columna el equivalente en grafía árabe vocalizada. Además de observaciones de tipo gramatical, aparecen aclaraciones sobre el sentido de las entradas en español y sinónimos en lo equivalentes árabes. Para aclarar el sentido y ejemplificar el uso de algunos términos en árabe, se intercalan en alguna ocasión fragmentos ilustrativos de autores árabes. A veces corrige la traducción de Alcalá, pero hay casos en los que lo hace partiendo del árabe clásico y no del andalusí, aunque también lo rectifica recurriendo frecuentemente al árabe marroquí porque lo considera idéntico al granadino, como se ha dicho. En este apartado también hay que hacer notar una diferencia con respecto a Alcalá: en los verbos, suprime el imperativo y deja solo el imperfectivo y perfectivo.

En cuanto al corpus léxico, suprime un considerable número de entradas, entre ellas la mayor parte de topónimos y gentilicios y todos los nombres propios de persona. Al mismo tiempo, introduce otras entradas nuevas o, como ocurre con las palabras malsonantes o tabú, las mantiene y añade otras. En el campo del vocabulario religioso, el islámico es minoritario y, en algún caso, con matiz despectivo, en tanto que el cristiano es más numeroso.

${ }^{67}$ DÍAZ. El dialecto árabe hispánico, 70. 


\subsection{José Lerchundi y su Vocabulario Español-Arábigo del dialecto de Marruecos $^{68}$}

El padre José Lerchundi nació en Orio (Guipúzcoa) en 1836 y murió en 1896. Profesó como franciscano a los diecinueve ${ }^{69}$ años, fue ordenado sacerdote en $1859 \mathrm{y}$, apenas tres años después, en 1862 se trasladó como misionero a Marruecos, concretamente a Tánger, y luego a Tetuán, donde aprendió árabe clásico y marroquí hasta alcanzar un elevado dominio en $\operatorname{ambos}^{70}$. En 1877 fue nombrado pro-prefecto de la Misión e Iglesia Marruecos, con sede en Tánger, lo que generó un conflicto por la oposición al nombramiento que adoptó el gobierno español, hasta el punto de obligarlo a volver a España. Durante tres años estuvo en Madrid, Granada y Santiago de Compostela. Durante su estancia en Granada, colaboró en la elaboración de un manual para la enseñanza del árabe, una crestomatía que incluía un breve diccionario para la traducción de los textos ${ }^{71}$, junto con el catedrático de lengua árabe de la Universidad de Granada Francisco Javier Simonet ${ }^{72}$. Finalmente, tras largas discusiones entre Madrid y Roma, se le permitió regresar a Marruecos a ocupar su cargo de prefecto, que mantuvo de 1880 a 1896, fecha de su fallecimiento en Tánger a los sesenta años. En esta última etapa de su vida desarrolló una intensa y amplísima actividad con creación de instituciones educativas, sanitarias y para la modernización de Marruecos, además de su labor de investigación lingüística y lexicográfica.

Por tanto, desde el principio de su llegada a Marruecos y al mismo tiempo que su actividad religiosa, desarrolló su labor filológica, resultado de la cual fue la publicación de varias obras de enseñanza de la lengua árabe. La primera de ellas fue Rudimentos del árabe

${ }^{68}$ J. M. LÓPEZ (1927). El padre Lerchundi: biografía documentada, Madrid, Imprenta Clásica Española; M. MANZANARES DE CIRRE (1971). Arabistas españoles del siglo XIX, prólogo de P. Chalmeta, Madrid, IHAC R. LOURIDO (ed.). Marruecos y el padre Lerchundi, Madrid, Mapfre, 1996; La misión franciscana de Marruecos, ayer y hoy. I Centenario P. José Lerchundi 1896-1996. Exposición, 16 de noviembre de 1996 al 16 de enero de 1997, Santiago de Compostela, Provincia Franciscana de Santiago, 1996, 45 p.; EL IMRANI. Lexicografía hispano-Árabe, cap. V, 263-299; LOURIDO. "Estudio preliminar”. En J. LERCHUNDI (1892). Vocabulario español-arábigo del dialecto de Marruecos, con gran número de voces usadas en Oriente y en la Argelia, Tánger, Imprenta de la Misión Católico-Española, XXIII + 863 p. Ed. facsímil con estudio preliminar por R. Lourido Díaz, Madrid, Agencia Española de Cooperación Internacional, 1999, VII-LXXXVI.

${ }^{69}$ LOURIDO. "Estudio preliminar", X. Por su parte, EL IMRANI. Lexicografía hispano-Árabe, 264, señala 21 años.

${ }^{70}$ Este aspecto es abordado en profundidad en el apartado “¿Por qué y cómo aprendió el árabe el P. Lerchundi?” incluido en LOURIDO. "Estudio preliminar", XVI-XXXII, que destaca la sorprendente rapidez con que aprendió árabe dialectal, pues el mismo año de su llegada ya escribió una carta en español con su traducción al árabe marroquí (p. XXXI). Al mismo respecto, v. a. H. BOUZINEB (1996). "El padre Lerchundi y su asimilación del árabe marroquí". Marruecos y el padre Lerchundi, Lourido (ed.), Madrid, MAPFRE, 149-174.

${ }^{71}$ Crestomatía arábigo-española, ó Colección de fragmentos históricos, geográficos y literarios relativos á España bajo el período de la dominación sarracénica: seguida de un vocabulario de todos los términos contenidos en dichos fragmentos, por el R.P.Fr. José Lerchundi y Francisco Javier Simonet. Granada: [s.n.], 1881 (Imprenta de Indalecio Ventura). XVI + $144+544$ p.; $23 \mathrm{~cm}$

${ }^{72}$ Ramón LOURIDO (1991). "Intercambio lingüístico entre Lerchundi y los arabistas europeos y marroquíes (La correspondencia de F. J. Simonet)". Homenaje al Prof. Jacinto Bosch Vilá, Granada, Universidad de Granada, t. II, 909-932. 
vulgar que se habla en el Imperio de Marruecos, cuya primera edición apareció en $1872^{73}$ y le valió el nombramiento de lector de lengua árabe en el Colegio de Misiones de Santiago de Compostela. Además de estos y otros libros, como una extensa Crestomatía arábigoespañola, ya citada, fundó en 1888 la imprenta de la Misión Católica Española en Tánger y una escuela de árabe en Tetuán para enseñar a frailes y seglares y facilitarles así su labor misionera.

Su Vocabulario Español-Arábigo del dialecto de Marruecos con gran número de voces usadas en Oriente y en la Argelia fue publicado en Tánger por la Imprenta de la Misión Católica Española en 1892 con un total de 834 páginas, más 29 de "Adiciones y correciones" (835-863), a dos columnas ${ }^{74}$. Además de esta primera edición, tuvo dos más: la segunda en $1916^{75}$ y la tercera en $1932^{76}$.

Es el resultado de treinta años de trabajo, desde 1862, cuando el autor comienza su estudio del árabe marroquí, hasta 1892, que aparece publicado el diccionario. Supone un avance para su época ${ }^{77}$, pues se trata de un diccionario específico de un dialecto árabe moderno, mientras que otras lexicografías bilingües europeas hacia el árabe que se elaboran a finales del siglo XIX, como la inglesa, estudiada por Nawal El-Badry ${ }^{78}$, solo empezaban a incluir en los diccionarios inglés-árabe algunos términos y expresiones coloquiales para facilitar la comunicación al estudioso de la lengua culta o literaria.

Las fuentes en las que se basó son tres ${ }^{79}$. En primer lugar, el contacto directo con los hablantes y la convivencia con el pueblo marroquí. En segundo lugar, las obras de

${ }^{73}$ J. LERCHUNDI. Rudimentos del árabe vulgar que se habla en el Imperio de Marruecos. Segunda edición. notablemente corregida y aumentada. Tánger: Imprenta de la Misión católico-española, 1889. XVI, 475, 56 p. Su éxito y demanda propició numerosas reediciones hasta mediados del siglo XX, como muestra la $7^{\mathrm{a}}$ ed. aparecida en Tánger: 1945.

${ }^{74}$ Vocabulario Español-Arábigo del Dialecto de Marruecos, con gran número de voces usadas en Oriente y en la Argelia, por el M. R. P. Fr. José Lerchundi, de la regular observancia de N. P. S. Francisco, superior de las Misiones Católico-Españolas en Marruecos. Tánger: Imprenta de la Misión Católico-Española, 1892. XXIII + 863 p. Tuvo una tirada de 1000 ejemplares. Ed. facsímil con estudio preliminar Ramón Lourido Díaz, Madrid, Agencia Española de Cooperación Internacional, 1999, LXXXVI + XXIII + 863 p., 22 cm.

${ }^{75}$ Vocabulario Español-Arábigo del Dialecto de Marruecos, con gran número de voces usadas en Oriente y en la Argelia. Segunda edición, corregida y aumentada con dos mil vocablos. Tánger, Tipografía de la Misión Católica, 1916, XXIII + 836 p. Tuvo una tirada de 1000 ejemplares.

${ }^{76}$ Vocabulario Español-Arábigo del Dialecto de Marruecos, con gran número de voces usadas en Oriente y en la Argelia. Tercera edición, corregida y aumentada con dos mil vocablos. Tánger, Tipografía Hispano-Arábiga de la Misión Católica, 1932, XXII + 856 p.

77 B. HERRERO MUÑOZ-COBO (1996). "Novedades en la obra lingüística del padre José Lerchundi". Marruecos y el padre Lerchundi, Lourido (ed.), Madrid, MAPFRE, 133-148.

${ }^{78}$ N. EL-BADRY (1986). "The development of the bilingual English-Arabic dictionary from the middle of the nineteenth century to the present". The history of lexicography. Papers from the Dictionary Research Centre Seminar at Exeter, March 1986, R. R. K. Hartmann (ed.), Ámsterdam / Filadelfia, J. Benjamins, 57-63. Véase además, desde una perspectiva más general, A. M. AL-KASIMI (1977). Linguistics and bilingual dictionaries, Leiden, Brill.

${ }^{79}$ LOURIDO. "Estudio preliminar", apartado "La fuentes del Vocabulario", LXXIV-LXXXVI. 
lexicografía árabe dialectal, tanto españolas como extranjeras, principalmente francesas y una italiana. En tercer lugar, los arabófonos cultos, a los que consultaba y con los que contrastaba el léxico ${ }^{80}$.

En cuanto al léxico castellano, la fuente en la que se basa es el Diccionario de la Academia en su duodécima edición de 1884.

El Vocabulario va precedido de una serie de "Advertencias importantes para el uso de este Vocabulario" (p. V-X) en las que Lerchundi explica el sistema y organización de las entradas y otros aspectos para facilitar la consulta y el manejo al lector, incluyendo observaciones sobre el árabe dialectal como, por ejemplo, vocalismo (p. VI, no 6). También advierte de la función de algunos signos tipográficos: el guión largo separa las distintas acepciones, el punto y coma separa los sinónimos árabes.

Además de estos signos y marcas lexicográficas, utiliza numerosas abreviaturas que no olvida reunir en un listado (XVII-XXIII), además de ofrecer otro listado específico para las abreviaturas referidas a "Autores y obras que se citan en este vocabulario" (XIII-XV).

Sigue un orden alfabético y a nivel de microestructura presenta las entradas españolas en mayúscula seguidas, en su caso, de sinónimos en minúscula y las equivalencias en grafía árabe sin vocalizar pero con transcripción. Indica el plural árabe señalando la terminación cuando es regular y con abreviatura: "pl. en in", "pl. en at". Además, marca los arabismos con: "voz ar." y las palabras árabes que recoge Cañes mediante la abreviatura "Cañ.". También incorpora alguna observación de tipo gramatical relativa al dialecto marroquí.

La selección del corpus léxico abarca nombres propios de persona marroquíes, bíblicos y andalusíes, mientras que los topónimos y gentilicios son principalmente marroquíes, aunque también se hallan otros. A diferencia de otros diccionarios históricos, en el del padre Lerchundi las palabras malsonantes o tabúes son escasas. En cambio, el vocabulario religioso islámico es abundante, no va acompañado de matices despectivos y cuando se trata de términos inexistentes en español estos se transcriben. A pesar de ello y lógicamente, el vocabulario religioso cristiano es más abundante y completo.

Hay que destacar, al igual que en el caso del diccionario de Patricio de la Torre, que contiene una interesante y abundante información sociológica, pero en este caso más rica y con datos sobre gastronomía, vestimenta, saludos y expresiones. Además, incluye las voces españolas que existen en el dialecto marroquí, muy numerosas ${ }^{81}$, y recurre a la habitual práctica lexicográfica de las agrupaciones ideológicas para reunir todos los términos y expresiones relacionados con una entrada.

\footnotetext{
${ }^{80}$ Véase en relación con este tema: LOURIDO. "Intercambio lingüístico entre Lerchundi y los arabistas europeos y marroquíes (La correspondencia de F. J. Simonet)".

${ }^{81}$ Así lo demuestran varios estudios, algunos de los cuales contabilizaban, ya antes de finalizar el primer tercio del siglo XX (por tanto, con varios decenios de presencia colonial española aún por delante), un millar y medio de hispanismos en el árabe marroquí. V. H. IBN AZZUZ (1931). Glosario de mil quinientas voces españolas usadas entre los marroquíes en el árabe vulgar, Madrid, CSIC, 132 p.
} 


\section{A MODO DE CONCLUSIÓN: ANÁLISIS LEXICOGRÁFICO GLOBAL}

A través de la descripción individualizada que se acaba de exponer se pueden observar algunas similitudes, paralelismos o divergencias que permiten caracterizar esta lexicografía bilingüe y extraer algunas conclusiones o, al menos, rasgos definitorios. Con este objetivo, en este apartado se presenta una caracterización general y análisis comparativo del conjunto de los diccionarios históricos descritos. Para ello, se examinan, en primer lugar, los rasgos generales relativos a la forma y a la estructura y, a continuación, los relacionados con el contenido.

\subsection{Forma y estructura}

Por lo que respecta a la macroestructura de estos diccionarios, siguen un orden alfabético, aunque no siempre riguroso, y, además, en el caso de Pedro de Alcalá, se divide el diccionario en tres categorías: verbo, nombre y partículas.

En cuanto a la microestructura y organización interna de los artículos, en la parte árabe separan las distintas acepciones mediante un punto, excepto Patricio José de la Torre, que deja un espacio en blanco. Por su parte, Francisco Cañes emplea el asterisco para señalar los arabismos. Aparte de estos signos, no suelen utilizar ningunas otras marcas lexicográficas.

Por lo que atañe al uso de abreviaturas, emplean un buen número y son lo bastante sistemáticos como para reunirlas en un listado específico. Sin embargo, no son suficientemente metódicos y rigurosos en su empleo. Concretamente, presentan dos defectos: a veces las abreviaturas aparecen en el texto de forma distinta a como están en el listado y en otras ocasiones la misma abreviatura se utiliza para dos cosas distintas.

En general no suelen incluir la categoría gramatical ni el género de los sustantivos. En los casos que sí lo hacen no siguen un criterio homogéneo y resultan bastante arbitrarios.

Es frecuente la práctica de agrupar bajo determinados artículos una serie de sinónimos y expresiones relacionadas para cubrir el campo semántico y las variaciones léxicas al mismo tiempo que se precisa y aquilata el significado de las palabras, práctica que tiene su origen en el Vocabulario español-latino de Nebrija.

Dentro de los aspectos formales de la lengua árabe se pueden señalar algunos errores ortográficos demasiado básicos para personas cuyo conocimiento de la lengua árabe era considerable. Tampoco se vocalizan de forma sistemática ni cuidada las palabras, lo que para un principiante, tanto de árabe clásico o estándar como de dialectal, supone una verdadera dificultad.

\subsection{Contenido}

La selección del vocabulario se realiza, básicamente, a partir del contenido de dos obras fundamentales de la lexicografía monolingüe española: el Vocabulario de Nebrija (¿1495?) y el Diccionario de la Academia. Sin embargo, no se atienen estrictamente al corpus de estas obras y excluyen algunas de las palabras que aparecen en ellas e incluyen otras ajenas. 
Análogamente, para las definiciones y equivalencias en árabe también se basan en los diccionarios monolingües de esta lengua.

La presencia de topónimos, gentilicios y nombres de persona es muy importante, quizás porque los diccionarios españoles en los que se basan incluyen este tipo de nombres, como es el caso del diccionario de Nebrija.

También resulta muy peculiar la gran cantidad de voces relacionadas con el sexo e incluso términos obscenos que se pueden encontrar en su repertorio. La anatomía y fisiología humana se recoge con los nombres de los órganos genitales, palabras y gestos propios del amor y del sexo, casi nunca con eufemismos a no ser que se trate ya de un vocablo o expresión demasiado groseros. La presencia de estos términos es sorprendente en obras elaboradas por religiosos cristianos y resulta difícil de explicar, si no es por la necesidad de comprender el habla del pueblo con el que los religiosos debían estar en contacto directo por su actividad misionera (incluido el confesionario, donde los términos debían de ser muy explícitos).

En relación con este aspecto, uno de los elementos importantes de un diccionario, ya sea bilingüe o monolingüe, es que contemple el factor sociolingüístico, cosa que estos diccionarios no hacen y al verter algunas palabras españolas que no tienen una carga semántica negativa, no se advierte al usuario de que en árabe sí la tiene y puede ser vulgar, grosera o tabú.

Por otro lado, el campo semántico del vocabulario religioso seleccionado está desequilibradamente representado y es mucho más abundante el cristiano que el islámico, lógicamente. En relación con el primero, se incluyen prácticas y fiestas religiosas cristianas, estructura eclesiástica, indumentaria sacerdotal o nombres de los libros que componen la Biblia. Por el contrario, al aclarar los términos islámicos se vierten muchas veces juicios despectivos hacia la religión o el Profeta del islam. En los casos en los que no existe en castellano el equivalente a un término islámico, como ocurre en algunas palabras religiosas, algunos autores transcriben términos árabes en caracteres latinos para la entrada y luego dan la definición del mismo en español.

Por lo que respecta a las definiciones y acepciones, en muchas ocasiones se acompaña al término de la entrada en español con unas aclaraciones o definiciones que, sin embargo, no siempre son lo suficientemente precisas y específicas que un diccionario exige y se quedan en una explicación demasiado general. También sucede que en lugar de ofrecer un término equivalente se recurre a traducir la parte definitoria de la entrada española y expresar con un giro en árabe lo que se puede decir en dicha lengua con una sola unidad léxica. Es decir, el método lexicográfico utilizado no es siempre el mismo que en general utilizan hoy los diccionarios bilingües, que dan términos equivalentes o correspondencias léxicas, sino que recurren a la definición de las entradas en algunas palabras. La excesiva extensión que este método genera se intenta evitar mediante la reducción de las definiciones que el diccionario de la Academia ofrece (para el caso de los que se basan en este: Cañes y Lerchundi). Así, cuando se trata de palabras con varias acepciones, se suele limitar a una sola, que suele ser la de carácter religioso en palabras que poseen este sentido. 
La mayoría de estos diccionarios son en cierto modo y al mismo tiempo una gramática sucinta, pues incluyen en muchos de sus artículos aspectos gramaticales de la lengua árabe, en general clásica o culta pero también con indicaciones esporádicas de árabe dialectal. Cuando aluden al dialecto, lo transcriben en caracteres latinos para facilitar su pronunciación. La transcripción sistemática de todas las palabras la realiza Lerchundi, dada la dificultad y peculiaridades fonéticas del árabe marroquí. Este es uno de los aspectos más importantes de estas obras: la inclusión de términos dialectales que en ningún otro diccionario se pueden encontrar y que permite reconstruir el dialecto andalusí o de otras regiones en los siglos pasados.

También contienen información sociológica ya que suelen incluir en algunos artículos datos acerca de las costumbres y tradiciones de los musulmanes habitantes del país en el que elaboran el diccionario. En este mismo sentido, los autores incluyen a veces relatos de experiencias personales y sus propias vivencias en los países en los que desarrollaban su labor evangelizadora.

Según A. El Imrani, estos frailes, respondiendo a su condición clerical, reflejan a través del vocabulario religioso que incluyen su ideología y tendencias proselitistas, por lo que adolecen de falta de objetividad y en general reflejan un cierto desprecio hacia la religión islámica. Por ejemplo, emiten juicios despectivos y equivocados con respecto al Islam ${ }^{82} \mathrm{y}$, por el contrario, ensalzan los nombres de personajes cristianos que mencionan.

Esta tendenciosidad así como los defectos señalados desde un análisis lexicográfico moderno no impiden, como el propio El Imrani reconoce ${ }^{83}$, que sean obras de gran mérito lexicográfico, pioneras en su campo y de enorme interés filológico y socio-cultural.

Francisco Vidal Castro

fvidal@ujaen.es

Universidad de Jaén

${ }^{82}$ EL IMRANI. Lexicografía hispano-Árabe, 300.
${ }^{83}$ Ibídem, 305. 